\title{
Modeling of Groundwater Pollution by Former Seawater in Submarine Groundwater Discharge Driven by Saltwater Intrusion
}

\author{
Wissam Al-Taliby ${ }^{1 *}$, Hadeel Dekhn² \\ 1 Department of Environmental Engineering, College of Engineering, University of Babylon, Babylon 51001, \\ Iraq \\ 2 Housing, Municipalities and Public Works, Soil Investigation Section, Construction Laboratories, Ministry of \\ Construction, Babylon 51001, Iraq \\ *Corresponding author's e-mail: waltaliby2011@my.fit.edu
}

\begin{abstract}
Coastal aquifers are usually vulnerable to contamination by saltwater intrusion. The degree of contamination depends on the amount of former seawater intruding the aquifer as submarine groundwater discharge (SGD). A three-dimensional numerical SEAWAT model was developed to provide insights to the responses of saltwater intrusion and amount of seawater portion of SGD, to groundwater withdrawal from four wells at different spatial locations. The results showed that saltwater wedge encroachment varies with a withdrawal rate and well location. Increasing withdrawal rates from $0.165 \mathrm{~m}^{3} / \mathrm{s}$ to $0.53166 \mathrm{~m}^{3} / \mathrm{s}$ resulted in a noticeable increase in wedge encroachment into the aquifer from $589 \mathrm{~m}$ to $1319 \mathrm{~m}$, respectively, regardless of the distance from the coastline. However, higher withdrawals from the wells closer to the coastline caused the hydraulic head near the seaside to drop below the terrestrial head, causing the saltwater wedge to be pushed back toward the sea. Simulations also showed that a coastal well might act as a hydraulic barrier that prevents the brackish zone from moving further inland, which is critically important in terms of groundwater management. Seawater contributed from 5\% to above 33\% in SGD. Although the withdrawal rates from Well 3 were 10 to 20 times larger than the Well 2 rates, the seawater contribution associated with Well 3 was about the same. This is attributed to the horizontal vicinity of Well 2 to the seacoast boundary compared to Well 3 even though Well 3 is deeper than Well 2, demonstrating that it is the horizontal location that governs the amount of abstracted former seawater.
\end{abstract}

Keywords: saltwater intrusion, SEAWAT, submarine groundwater discharge, groundwater.

\section{INTRODUCTION}

Coastal areas provide economic and environmental support to many vibrant and densely populated cities and ecosystems in many regions of the world. For instance, although coastal watershed counties in the United States constitute less than $20 \%$ of the country's conterminous landmass, they are home to about $52 \%$ of the county's population [NOAA, 1998]. It was reported that 99 persons $/ 2.6 \mathrm{~km}^{2}$ were added to those watershed communities from 1970 to 2010, and this number is projected to increase [NOAA's National Ocean Service, 2013]. Globally, coastal communities are home to about $70 \%$ of the world's population [Bear et al., 1999]. Management of all facets of such fast-growing coastal communities, including population, industry, agriculture, and ecosystems, requires sustainable management and protection of available natural resources. A reliable source of freshwater is perhaps one of the most substantial and precious needs required to sustain the prosperity of those vibrant regions.

Freshwater might be abundant from several surface water sources such as rivers, lakes, canals, and springs. However, in many coastal regions, groundwater is the primary or the sole source of freshwater, especially in arid and semiarid areas. For example, in Florida, freshwater withdrawal from groundwater accounted for $65 \%$ of the total freshwater use in 2012 [Marella, 2015]. Increased groundwater withdrawal and 
overuse due to increased development in coastal regions usually make this resource vulnerable to several issues, including contamination and supply depletion. Overuse of groundwater results in lowered groundwater storage in coastal aquifers, which eventually leads to reduced fresh groundwater fluxes to coastal rivers, canals, estuaries, and other coastal ecosystems in addition to lowered water levels in lakes and ponds. Perhaps, one of the major groundwater contamination issues that result from groundwater overuse in coastal regions is the saltwater intrusion into freshwater coastal aquifers, due to their vicinity and direct hydraulic link to seas and oceans. Saltwater intrusion occurs by the lateral movement or encroachment of the higher density saline water from the seaside towards the lower density inland fresh groundwater aquifers.

Generally, the fresh groundwater generated from terrestrial sources in coastal aquifers flows over the higher density saltwater that intrudes the aquifer and discharges into the sea, which limits the landward extent of saltwater intrusion, as illustrated in Figure 1. However, extensive pumping of groundwater from coastal wells results in a subsequent lowering of inland groundwater hydraulic head and disturbs the dynamic balance between the fresh groundwater and the saline water, thereby accelerating saltwater wedge movement further inland. The fresh groundwater in coastal regions has a total dissolved solids (TDS) concentration of less than $1,000 \mathrm{mg} / \mathrm{L}$ with a chloride concentration of less than $20 \mathrm{mg} / \mathrm{L}$ [Barlow, 2003]. However, the TDS concentration in seawater is about $35,000 \mathrm{mg} / \mathrm{L}$, with chloride being the main constituent with a concentration of about 19,000 mg/L [Barlow, 2003; Hem, 1989; Stumm and Morgan, 1981]. Thus, mixing fresh groundwater with such small amount as two to three percent of seawater can be deleterious to water quality as well as suitability for human consumption and other uses. In extreme cases, the saltwater intrusion may lead to the termination of groundwater supply wells when the TDS concentration exceeds the maximum drinking water standards.

When saltwater intrusion occurs, the fresh groundwater and saltwater behave as two miscible fluids, and thus, they merge in a brackish transition zone (also known as dispersion zone) where the TDS concentration varies from that of freshwater on the land side to that of seawater on the seaside [Bear, 1979] as shown in Figure 1. The saltwater at the bottom of the aquifer, due to its higher density, moves towards the freshwater side and mixes with fresh groundwater. After being mixed with freshwater, its density becomes lower, and thus, it recirculates back to the sea at the upper part of the sea-aquifer interface. The sum of groundwater discharging to the sea, including the terrestrial fresh groundwater and the recirculated seawater, is defined as submarine groundwater discharge (SGD) which is also seen to be complementary to saltwater intrusion [Taniguchi et al., 2002]. SGD represents another source of contamination that needs to be considered in any coastal area management program in addition to the previously mentioned fresh groundwater salinization issues related to saltwater intrusion. Several previous investigations showed that SGD acts as an important pathway for land-washed contaminant transport, especially nutrients, into coastal ecosystems and marine environments [e.g., Szymczycha et al., 2020; Reay, 2004; Crusius et al., 2005; Valiela et al., 1978; Valiela et al., 2002].

Inside the brackish transition zone, the groundwater flow is governed by the hydraulic gradient, while salt transport is governed by the concentration gradient. Therefore, saltwater intrusion is analyzed and solved as a variable-density problem where fluid density is a function of TDS concentration. Thus, the equations of flow and salt transport are coupled. Therefore, saltwater intrusion affects the flow regime and the SGD amount in coastal zones; consequently, it influences the nutrient transport in coastal environments.

The first known study that attempted to analyze saltwater intrusion was conducted by [Henry, 1964] who developed a steady-state quasi analytical solution of a hypothetical unconfined coastal aquifer. The aquifer was $2 \mathrm{~m}$ long, $2 \mathrm{~m}$ deep, and $1 \mathrm{~m}$ wide, where a flux of fresh groundwater flows from the inland boundary towards the sea boundary while seawater encroachment extends inland. Thereafter, many researchers, motivated by the available Henry's analytical solution, have used the original or modified versions of Henry's problem either to compare their solutions to Henry's solution or to use it as a benchmark to their numerical codes for analyzing the saltwater intrusion problems [e.g. Pinder and Cooper, 1970; Lee and Cheng, 1974; Ségol et al., 1975; Voss and Souza, 1987; Segol, 1993; Croucher and O'Sullivan, 1995; Simpson and Clement, 2003; Dentz et al., 2006].

Several other researchers have investigated saltwater intrusion and the related SGD for other 


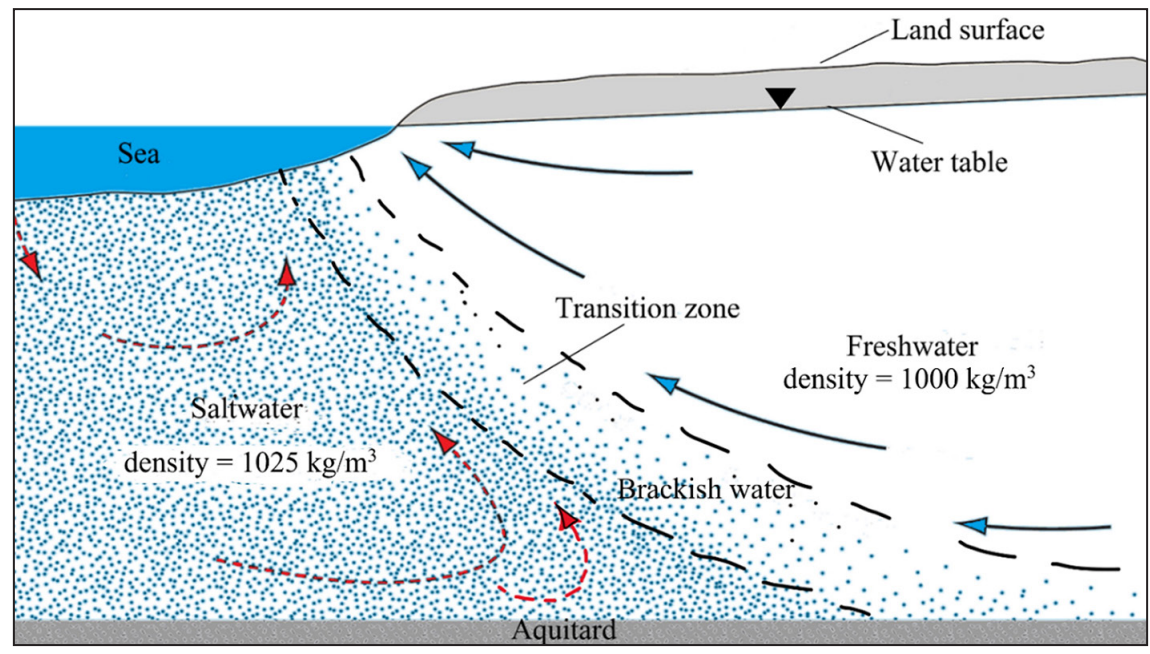

Figure 1. Transition zone and seawater circulation in a surficial coastal aquifer (modified from: https://water.usgs.gov/ogw/gwrp/saltwater/salt.html)

groundwater problems that had dimensions and/ or hydraulic properties different than those used in [Henry, 1964]. In his work, [Smith, 2004] has used both FEFLOW [Diersch, 2002] and SUTRA [Voss, 1984] codes, while [Motz and Sedighi, 2013] have used SEAWAT [Langevin et al., 2008] code to develop the numerical models for investigating saltwater intrusion and the recirculated component of SGD relative to the fresh groundwater flux in the problems that had similar geometry yet larger dimensions than that of Henry's. [Smith, 2004] concluded that the seawater recirculated portion of mixed convection SGD is predictable and was able to determine its nondimensional controls. [Motz and Sedighi, 2013] found in their numerical investigation that increasing a dimensionless ratio of terrestrial fresh groundwater flux to the density-driven buoyancy flux caused the saltwater intrusion and the amount of recirculated SGD component to decrease significantly. [Al-Taliby and Pandit, 2017] have used SEAWAT 2000 version 4 [Langevin et al., 2008] to simulate saltwater iso-salinity contours and percent of recirculated SGD at different hydrologic and hydraulic properties of the original Henry's problem. [Al-Taliby and Pandit, 2017] compared their simulations with and without taking variable-density effects to account, which corresponds to coupled and uncoupled solutions, respectively.

In the work described in this study, several numerical simulations were conducted to analyze saltwater intrusion and the resulting former seawater percentage in SGD, termed herein as
$P Q$, that intrudes the aquifer and mixes with freshwater. The analyses were conducted in the presence of different withdrawal rates and different well locations in a large-scale threedimensional model. The main objective of the analysis was to provide quantitative and qualitative insights into saltwater intrusion and the $P Q_{\text {s }}$ that contaminate fresh groundwater as well as their responses to the changes in groundwater withdrawal rates and horizontal and vertical locations. With the aim of adequately representing the variable-density nature in the brackish transition zone between fresh groundwater and saltwater, the flow and transport equations were solved in a coupled scheme. In coupled solutions, the fluid density in the flow equation is obtained and updated after each transport equation's solution iteration based on the TDS concentration in the flow field. Therefore, numerical modeling in this research was accomplished using SEAWAT 2000 version 4 code [Langevin et al., 2008], which is a three-dimensional groundwater flow and transport program that is capable of simulating the variable-density effects in a coupled mode. SEAWAT code is a combination of MODFLOW [McDonald and Harbaugh, 1988] and MT3DMS [Zheng and Wang, 1999] for solving the flow and transport equations in finite-difference technique after being modified for inclusion of density effects. More details about the governing equations of flow and transport used in SEAWAT, including the mathematical derivation and modification, can be found in the SEAWAT manual [Guo and Langevin, 2002]. 


\section{MATERIALS AND METHODS}

\section{Numerical model description}

The 3D model domain is $2000 \mathrm{~m}$ long in the $\mathrm{x}$-direction, $1000 \mathrm{~m}$ wide in the $\mathrm{y}$-direction, and $100 \mathrm{~m}$ deep in the z-direction (Fig. 2). Discretization of the model finite-difference grid is selected with 20 columns, 10 rows, and 10 layers with a grid spacing of $\Delta x=\Delta y=100 \mathrm{~m}$ and $\Delta \mathrm{z}=10 \mathrm{~m}$. The seaside hydrostatic boundary is modeled as a specified head and concentration boundary. SEAWAT internally converts the head data at the sea boundary into equivalent freshwater hydraulic heads. The salt concentration used at the sea boundary is a normalized seawater concentration of 1 , which is equivalent to the TDS concentration of $35,000 \mathrm{mg} / \mathrm{L}$. The inland boundary is simulated with injection wells to provide a constant flux of fresh groundwater with a total rate $\left(Q_{f}\right)$ of $0.66 \mathrm{~m}^{3} / \mathrm{sec}$ and zero salt concentration. Four extraction wells were embedded in the numerical model with the horizontal and vertical distribution (Fig. 3). Wells 1 and 2 extract the water from layer 2, while wells 3 and 4 extract the water from the deeper regions of the aquifer in layer 6 . Horizontally, well 4 is located farther from the cluster of wells 1 through 3. No-flow boundaries (Neumann boundaries) were assigned to the rest of the model boundaries. The aquifer is unconfined, homogeneous, and anisotropic with respect to hydraulic conductivity. The details of the aquifer parameters pertaining to the numerical model are provided in Table 1.

\section{Numerical experiments}

Several numerical experiments were run to simulate the advancement of saltwater intrusion wedge and SGD under different groundwater withdrawal scenarios. In all experiments, SEAWAT was run to reach a steady-state after a simulation time of 3000 days. The first simulation involved no pumping from all wells. The rest of the model runs simulated the saltwater intrusion and SGD conditions when one of the wells was pumping, while the other three wells were off. The ranges of withdrawal rates $\left(Q_{o}\right)$ for the Wells 1 through 4 were $(0.0183-0.165) \mathrm{m}^{3} / \mathrm{sec}$, $(0.183-0.348) \mathrm{m}^{3} / \mathrm{sec},(0.357-0.532) \mathrm{m}^{3} / \mathrm{sec}$, and $(0.55-0.66) \mathrm{m}^{3} / \mathrm{sec}$, respectively. For evaluating the degree of saltwater wedge advancement in this work, a simulated iso-salinity contour of 0.03 (equivalent to the TDS concentration of about $1000 \mathrm{mg} / \mathrm{L}$ ) was considered as the front of the saltwater wedge.

\section{RESULTS AND DISCUSSION}

The simulated distribution of salinity in the entire aquifer under no-pumping conditions presented in Figure 4 clearly shows how saltwater intrusion occurs on the seaside causing the groundwater salinity to vary from that of seawater to that of freshwater. In order to provide a comprehensive representation of the entire brackish transition zone, the iso-salinity contours ranging from 0.9 to 0.03 were presented for two selected withdrawal rates for each of the four wells, as shown in Figure 5. The obtained results show how the extent of saltwater wedge encroachment into the aquifer varies with a withdrawal rate and well

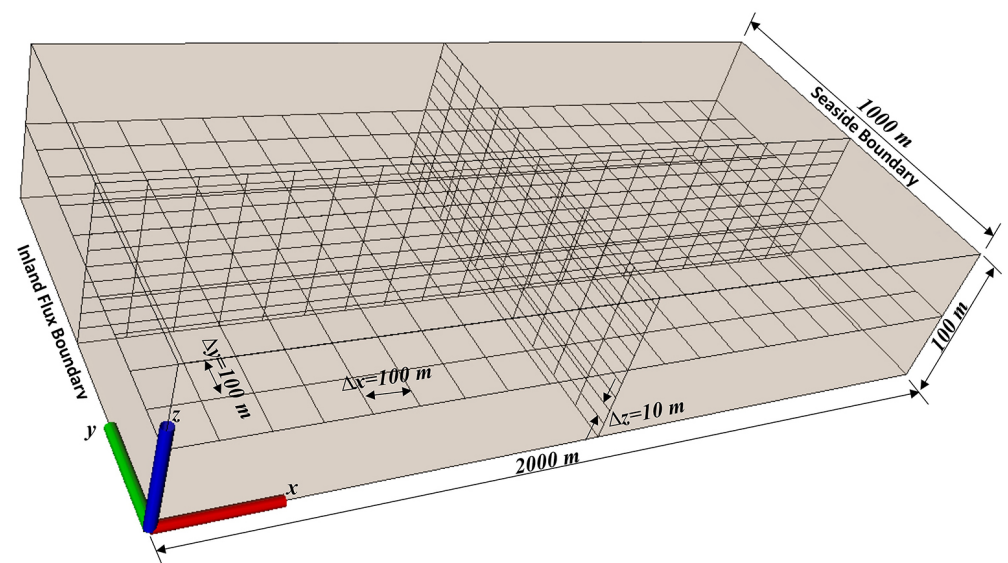

Figure 2. Finite difference grid of the coastal aquifer numerical model 


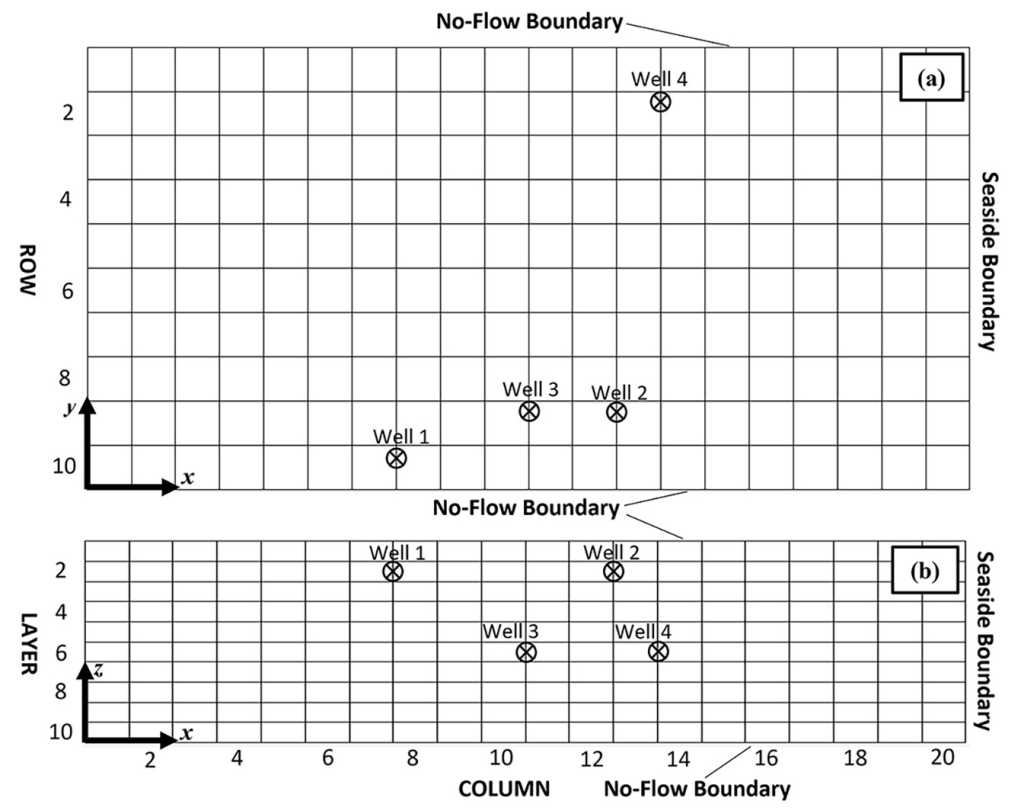

Figure 3. Locations of extraction wells; (a) horizontal locations in $x-y$ plain, (b) vertical locations in $x-z$ plain

location. The salinity of extracted groundwater at each well location was simulated when one well was pumping within the selected withdrawal ranges mentioned previously while the other three wells were off, as shown in Figure 6. The total inflow across the seaside boundary, which represents the part of SGD that originates from the sea $\left(Q_{s}\right)$ and enters the aquifer at the lower part of the sea-aquifer interface, was obtained from the fluid mass balance. The results of numerical simulations showed that the amounts of $Q_{s}$ increased along with groundwater extraction (Fig. 7).

The groundwater flow system in coastal aquifers is either dominated by the advective fresh groundwater flux or by the vertical

Table 1. Aquifer parameters used in the SEAWAT model

\begin{tabular}{|l|c|c|}
\hline \multicolumn{1}{|c|}{ Parameter } & Magnitude & Unit \\
\hline$\Theta$ (porosity) & 0.35 & - \\
\hline$D_{m}$ (molecular diffusion coefficient) & 0.57024 & $\mathrm{~m}^{2} / \mathrm{d}$ \\
\hline $\begin{array}{l}K_{x} \text { (hydraulic conductivity in the } \\
\text { X-direction) }\end{array}$ & 19.872 & $\mathrm{~m} / \mathrm{d}$ \\
\hline $\begin{array}{l}K_{y} \text { (hydraulic conductivity in the } \\
\text { y-direction) }\end{array}$ & 1.9872 & $\mathrm{~m} / \mathrm{d}$ \\
\hline $\begin{array}{l}K_{z} \text { (hydraulic conductivity in the } \\
z-\text {-direction) }\end{array}$ & 0.01987 & $\mathrm{~m} / \mathrm{d}$ \\
\hline$\alpha_{L}$ (longitudinal dispersivity) & 100 & $\mathrm{~m}$ \\
\hline$\alpha_{T}$ (transverse dispersivity) & 10 & $\mathrm{~m}$ \\
\hline$Q_{f}$ (fresh groundwater flux) & 0.66 & $\mathrm{~m} / \mathrm{s}$ \\
\hline $\begin{array}{l}C_{s} \text { (normalized seawater } \\
\text { concentration) }\end{array}$ & 1 & - \\
\hline$\rho_{s}$ (seawater density) & 1025 & $\mathrm{~kg} / \mathrm{m}^{3}$ \\
\hline$\rho_{f}$ (freshwater density) & 1000 & $\mathrm{~kg} / \mathrm{m}^{3}$ \\
\hline
\end{tabular}

density-dependent buoyancy flux, depending on the dimensionless ratio $a_{z}$ calculated by [Motz and Sedighi, 2013]:

$$
a_{z}=\frac{Q_{f}^{\prime}}{K_{z} d \epsilon}
$$

where: $Q_{f}^{\prime}-$ fresh groundwater flow at the inland flux boundary per unit width of the boundary $\left(\mathrm{L}^{2} \mathrm{~T}^{-1}\right)$;

$K_{z}$ - vertical hydraulic conductivity $\left(\mathrm{LT}^{-1}\right)$, $d=$ aquifer depth in the z-direction (L), and;

$$
\epsilon=\frac{\rho_{s}-\rho_{f}}{\rho_{f}}
$$

An $a_{z}$ greater than 1 implies that the advective groundwater flow is dominating the system, and an $a_{z}$ less than 1 implies that the vertical density-dependent buoyancy flux dominates the flow system. In this study, substituting the values from Table 1 in the equations above, an $a_{z}=1148$ is obtained. The obtained $a_{z}$ implies that the aquifer system selected in this study is dominated by fresh groundwater flux-driven advective forces. This result explains why groundwater flow direction is all toward the sea, and no SGD originating from the sea $\left(Q_{s}\right)$ is occurring into the aquifer in the case of no-pumping. Despite that no groundwater is being extracted from the aquifer and that all terrestrial groundwater drainage is 


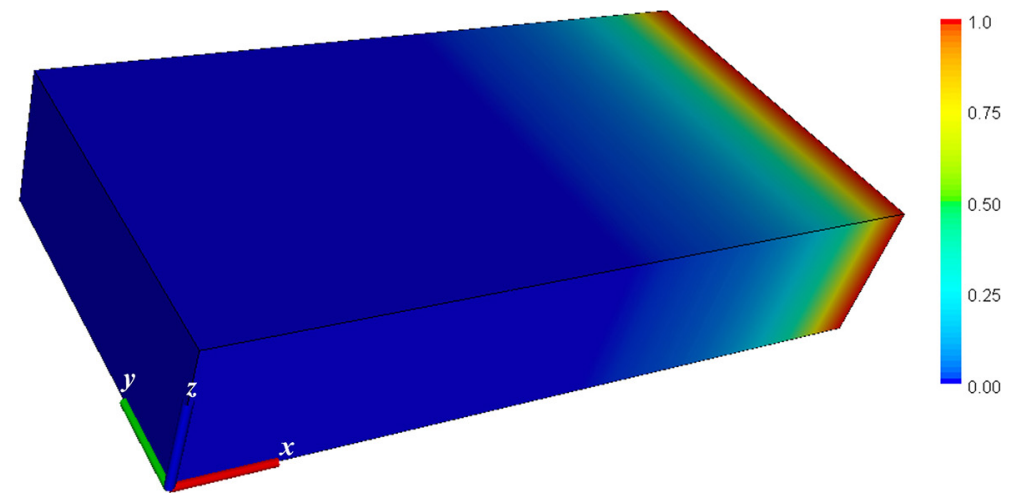

Figure 4. Salinity distribution in the entire aquifer under the no-pumping condition

toward the sea, saltwater intrusion is still seen to occur, as can be depicted from the color ramp representation of the simulated salinity in Figure 4. Thus, the salt transport from the seaside toward the aquifer occurs mainly due to dispersion and molecular diffusion.

The simulated salinity distributions presented in Figure 5 showed a brackish mixing zone that expanded increasingly deeper into the aquifer with increasing withdrawal rates. Lower withdrawal rates from Well 1 (Fig. 5a) created a salinity distribution that is not significantly different from the no-pumping condition. However, increasing the withdrawal rate from $0.01833 \mathrm{~m}^{3} / \mathrm{sec}$ to $0.165 \mathrm{~m}^{3} / \mathrm{sec}$ induced a little bulge in the 0.003 iso-salinity contour (right side of Fig. 5a). The
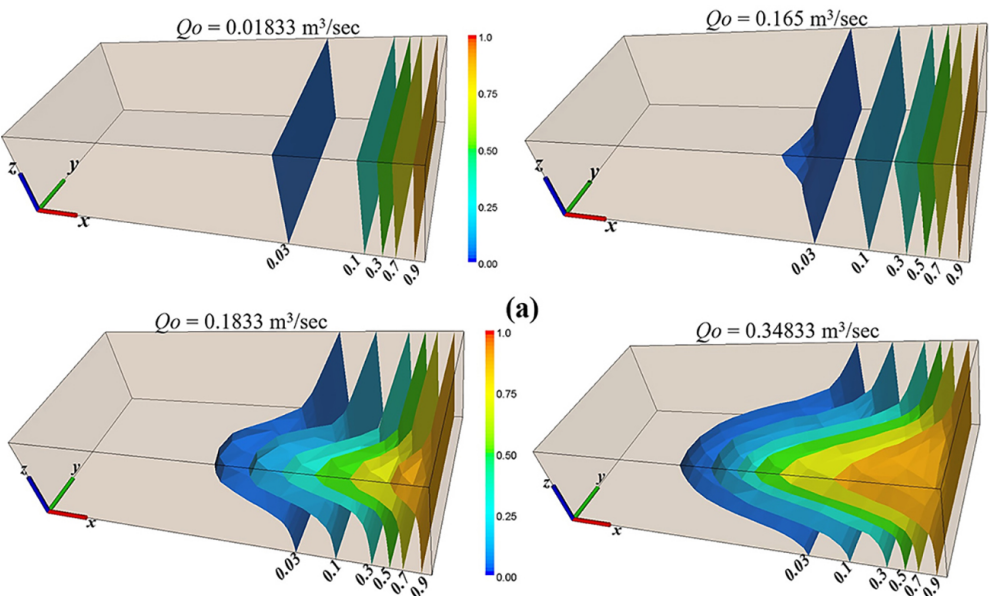

(a)
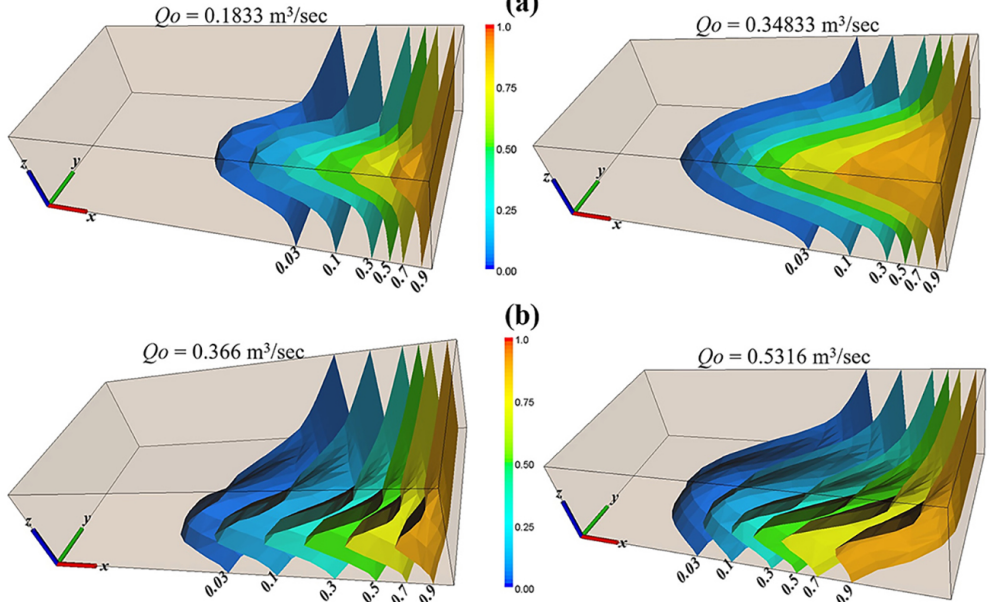

(b)
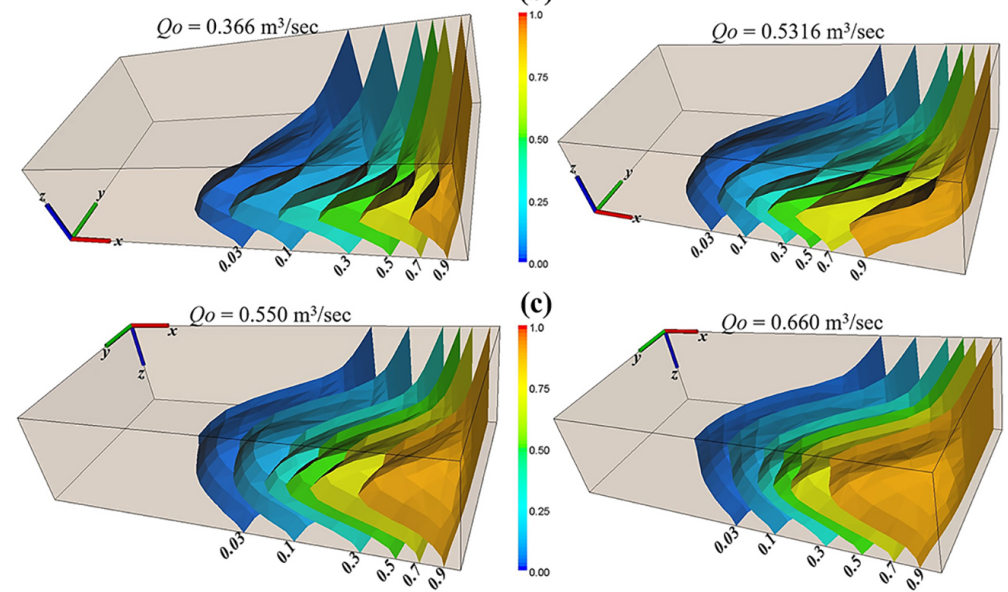

(d)

Figure 5. Simulated iso-salinity distributions in the entire aquifer under different withdrawal rates $\left(Q_{o}\right)$ at: (a) Well 1, (b) Well 2, (c) Well 3, and (d) Well 4 
shapes of simulated salinity distributions were noticeably affected by both withdrawal rate and well location, where they seemed to be directed toward the pumping wells and expanding deeper with increasing withdrawal rate (Fig. 5b-d). The landward extent of the brackish transition zone encroachment is measured as the location of the 0.03 iso-salinity contour measured from the coastline. It was noticed that the encroachment extent was increasing from $589 \mathrm{~m}$ when Well 1 was pumping with a rate of $0.165 \mathrm{~m}^{3} / \mathrm{sec}$ (Fig. 5a), to $1136 \mathrm{~m}$ when Well 2 was pumping with a rate ranging from 0.1833 to $0.34833 \mathrm{~m}^{3} / \mathrm{sec}$ (Fig. 5b), and then to $1319 \mathrm{~m}$ when groundwater was being extracted from Well 3 with a rate ranging from 0.3666 to $0.53166 \mathrm{~m}^{3} / \mathrm{sec}$ (Fig. $5 \mathrm{c}$ ). However, although groundwater was still extracted from Well 4 with higher rates of $0.55 \mathrm{~m}^{3} / \mathrm{sec}$ and $0.66 \mathrm{~m}^{3} / \mathrm{sec}$ (Fig. 5d) compared to the withdrawal rates from Well 3, the extent of the brackish transition zone encroachment into the aquifer was noticed to decrease back into $1090 \mathrm{~m}$. This retreat in the landward extent of the saltwater wedge is attributed to the vicinity of Well 4 to the coastline, accompanied by higher abstraction rates which caused a drop in the hydraulic head at the seaside, and as a result, the seaward fresh groundwater flux forces the salt body further back toward the sea. The percent seawater in SGD, $\left(P Q_{s}\right)$, was calculated using equation 3 to quantify seawater contribution:

$$
P Q_{s}=\frac{Q_{s}}{Q_{f}} \times 100
$$

A noticeable correlation between the salinity of extracted groundwater on the one hand, and both the location of the operating well and the withdrawal rate, on the other hand, is depicted in Fig. 6. The groundwater withdrawal from Well 1 did not seem to make any noticeable difference in the detected salinity at all four wells, including Well 1 itself (Fig. 6a) where salinity kept below 0.03 , which implies a TDS $<1000 \mathrm{mg} / \mathrm{L}$. Wells 2 and 3, which are spatially close to Well 1 are also noticed not to be affected by their vicinity to the operating Well 1 (Fig. 3a). Operating Well 2 resulted in extracting brackish groundwater with detected salinity above 0.05 at its lower withdrawal rate and spiking higher to 0.25 at the highest rate of abstraction (Fig. 6b). Although groundwater extraction from Well 2 resulted in increased salinity at Well 2, the groundwater salinity at the other three wells locations was not affected and kept within freshwater limits. Despite their spatial vicinity to Well 2, the salinity of groundwater at both Wells 1 and 3 (Fig. 3a) was not affected, owing to their location on the inland side of the operating Well 2, which acts as a hydraulic barrier for them. Well 2 causes the saltwater wedge to retreat, thereby protecting the fresh groundwater on the inland side from further pollution. The dropdown created by Well 2 pushed the saltwater wedge towards the well location away from Well 4, which is located away on the other side of the aquifer (Fig. 3a) where the fresh groundwater flux is dominating and sustaining salinity below 0.03 (Fig. 6b). High groundwater salinity ranging from 0.075 to more than 0.21 was simulated to be detected at Well 3 when the well was pumping groundwater over the simulated withdrawal ranges (Fig. 6c). This implies that the groundwater extracted from Well 3 would be brackish over the entire withdrawal rates. Once Well 3 starts pumping groundwater within the range of withdrawal rates shown in Fig. 6c, Well 2, which is located on the seaside from the operating Well 3, becomes surrounded by the body of the intruding brackish transition zone with groundwater salinity that reaches more than 0.1 (Fig. 6c). However, Well 3 behaves as a hydraulic barrier for Well 1 on the freshwater inland side, capturing the brackish zone from reaching Well 1. Similar to the case where Well 2 was operating, Well 4 is far from being polluted owing to its farther location on the other side of the aquifer (Figs. 3a and $6 c)$. When groundwater is withdrawn from Well 4 , the salinity at the well location reaches more than 0.45 , indicating brackish groundwater with TDS $>15,000 \mathrm{mg} / \mathrm{L}$ (Fig. 6d). Due to the large drawdown created by Well 4 , the brackish transition zone is significantly shifted toward the well away from Wells 1, 2, and 3 (Fig. 3d), and this explains the negligible salinity detected at those wells (Fig. 6d).

Figure 7 demonstrates a strong linear relationship between groundwater withdrawal rate and the seawater portion in the SGD entering the aquifer from the sea boundary. Numerical simulations demonstrated that no seawater entered the aquifer when Well 1 was operating within the entire low withdrawal rates used in this study. However, the significant contribution of seawater into SGD was simulated when groundwater was being extracted from the other three wells separately, one well at a time. With Well 2 operating, 

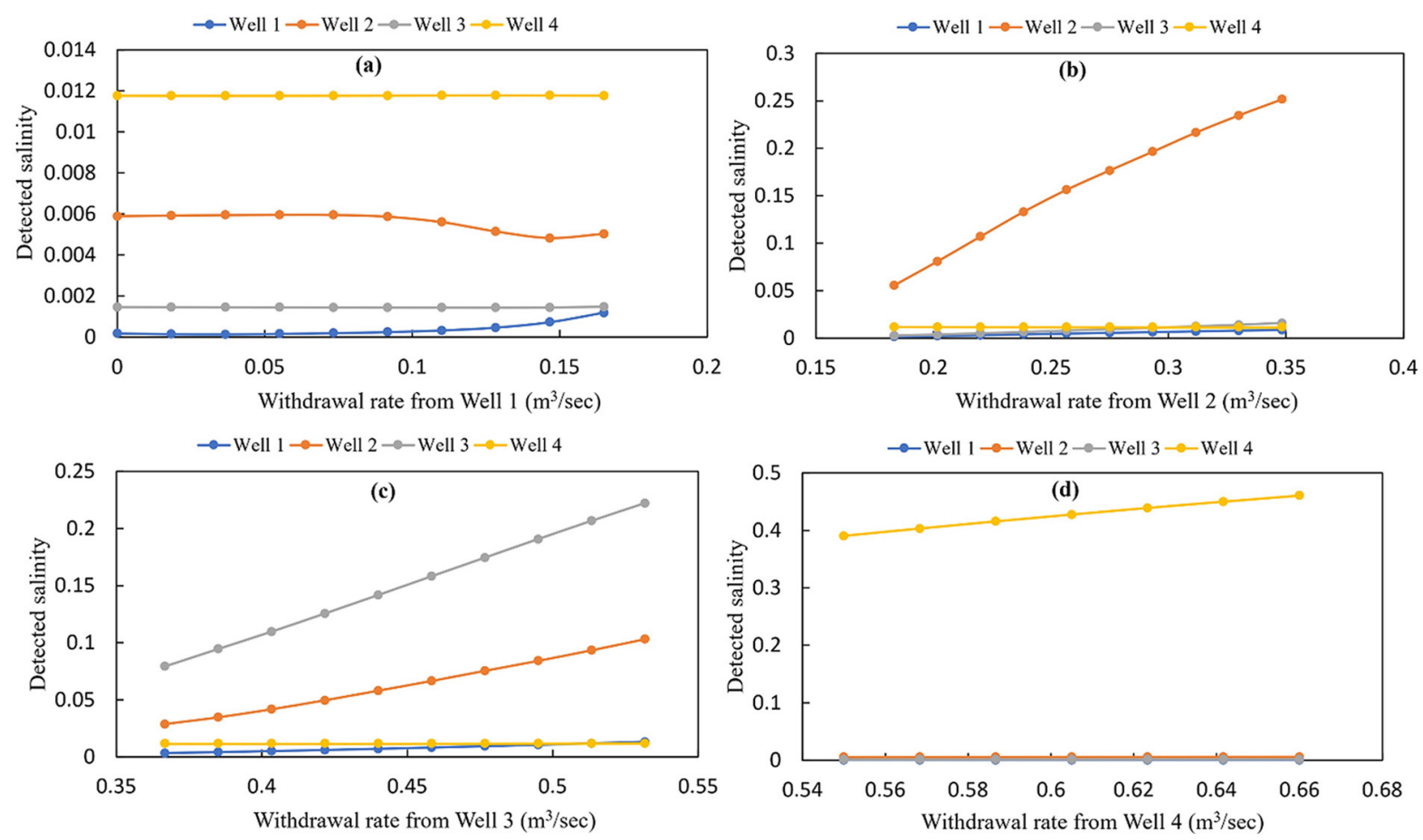

Figure 6. Simulated salinity detected at the extraction wells when one well is pumping while the rest are off: (a) Well 1 is pumping, (b) Well 2 is pumping, (c) Well 3 is pumping, and (d) Well 4 is pumping

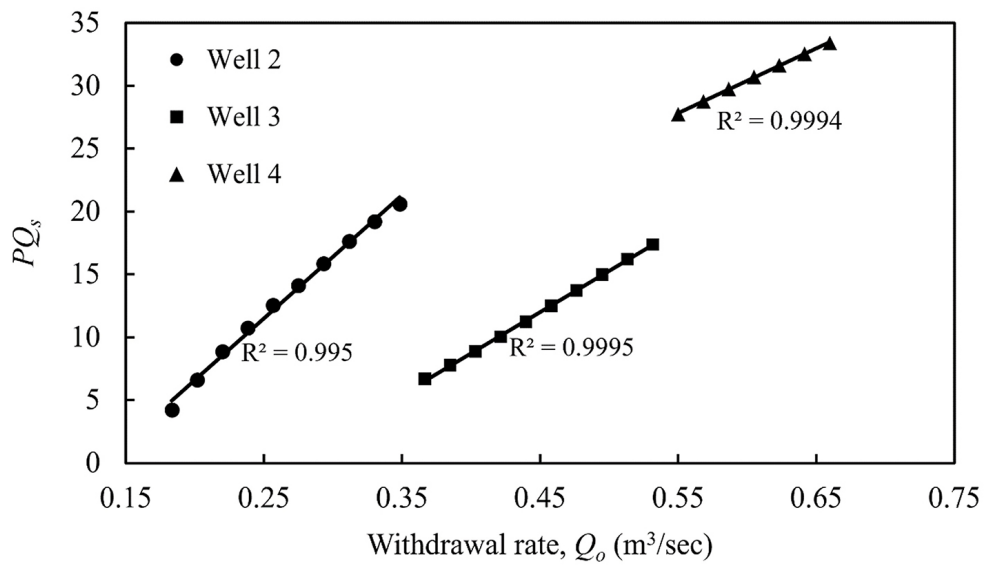

Figure 7. Simulated percent SDG contributed by seawater under different withdrawal rates and well locations

seawater contributed from about $5 \%$ to more than $20 \%$ in SGD (Fig. 7). Although the withdrawal rates from Well 3 were 10 to 20 times larger than Well 2 extraction rates, the seawater contribution associated with Well 3 was about the same as with Well 2 and was even slightly lower at the highest withdrawal rates where it reached $17 \%$ at a withdrawal rate of $0.53166 \mathrm{~m}^{3} / \mathrm{sec}$ compared to $21 \%$ at a rate of $0.34833 \mathrm{~m}^{3} / \mathrm{sec}$ from Well 2. This is attributed to the horizontal vicinity of Well 2 to the seacoast boundary compared to Well 3, even though Well 3 is deeper than Well 2. These results demonstrate that it is the horizontal location that governs over the vertical location of the well in terms of the amount of seawater that can be abstracted. With Well 4, which is the closest to the sea (Fig. 3a), the seawater contribution reached its highest values ranging from $28 \%$ to $33 \%$ (Fig. 7). In all cases, those seawater contributions were mixed with freshwater causing substantial contamination given those elevated percentages.

\section{CONCLUSIONS}

Extensive groundwater abstraction from coastal aquifers generates a saline SGD component that originates from the sea. This discharge 
component is termed herein as former seawater. The former seawater flows into the aquifer at the bottom of the aquifer-sea interface and mixes with the fresh terrestrial groundwater, which increases the salinity of abstracted groundwater substantially. In this study, the extent of saltwater wedge encroachment into a coastal aquifer and the associated amount of former seawater were modeled and analyzed. Several numerical simulations were conducted using a three-dimensional variable-density flow and transport model developed using SEAWAT code. The analyses were conducted in the presence of a wide range of withdrawal rates abstracted from four wells (Well 1 through 4) located at different spatial zones within the domain of the large-scale three-dimensional model. The model was run with only one of the wells extracting groundwater at each time while the other three wells were off.

Extracting groundwater from the wells that are farther inland caused the saltwater wedge to intrude deeper into the aquifer with increasing withdrawal rates regardless of the well vicinity from the coastline. For example, extracting the groundwater from Well 3 with higher rates than those from Well 2 caused the saltwater wedge to intrude deeper in the aquifer, even though Well 2 is closer to the sea than Well 3. However, higher withdrawal rates from the wells closer to the coastline induced a drop in the hydraulic head near the seaside below the terrestrial groundwater head, thereby causing the saltwater wedge to retreat toward the sea. In terms of former seawater contribution in SGD, the wells that are farther inland (Wells 2 and 3) produced almost similar former seawater contributions over the entire range of groundwater withdrawals, although Well 3 is closer to the sea and pumping with higher rates. However, moving closer to the seaside, at Well 4 , former seawater contribution increased significantly and reached up to $33 \%$ with increasing withdrawal rates. Simulations also showed that groundwater extraction from a well shifted the wedge towards that well and therefore caused the salinity of groundwater to increase at the operating well location and the aquifer on the seaside and decrease on the inland side. This implies that a well may act as a hydraulic barrier that prevents the brackish zone from moving further inland, which is critically important in terms of groundwater management practices [Gurauskiene, 2006, Eco-design methodology for electrical and electronic equipment industry].

\section{REFERENCES}

1. Al-Taliby W., Pandit A. 2017. Comparison of solutions of coupled and uncoupled models for the Henry problem. World Environmental and Water Resources Congress, 89-102.

2. Barlow P.M. 2003. Groundwater in fresh water-salt water environments of the Atlantic Coast, U.S. Geological Survey Circular, 1262, 121.

3. Bear J. 1979. Hydraulics of groundwater, McGrawHill series in water resources and environmental engineering. McGraw-Hill, New York.

4. Bear J., Cheng A.H., Sorek S., Ouazar D., Herrera I. 1999. Seawater intrusion in coastal aquifers: concepts, methods and practices Springer Science $\&$ Business Media. The Netherlands: Kluwer Academic Publishers, 14.

5. Croucher A.E., O’Sullivan M.J. 1995. The henry problem for saltwater intrusion. Water Resources Research, 31(7), 1809-1814.

6. Crusius J., Koopmans D., Bratton J.F., Charette M.A., Kroeger K., Henderson P., Colman J.A. 2005. Submarine groundwater discharge to a small estuary estimated from radon and salinity measurements and a box model. Biogeosciences, 2(2), 141-157.

7. Dentz M., Tartakovsky D.M., Abarka E., Guadagnini A., Sanchez-Vila X., Carrera J. 2006. Variabledensity flow in porous media. Journal of Fluid Mechanics, 561, 209-235.

8. Diersch H.J. 2002. FEFLOW finite element subsurface flow and transport simulation system: DHIWASY Software. reference manual, DHI-WASY $\mathrm{GmbH}$. Institute for Water Resources Planning and Systems Research, Berlin, Germany, 3, 42.

9. Guo W., Langevin C.D. 2002. User's Guide to SEAWAT: A Computer Program for Simulation of Three-Dimensional Variable-Density Ground-Water Flow. Techniques of Water-Resources Investigations 6-A7, USGS, Tallahassee, Florida.

10. Hem J.D. 1989. Study and interpretation of the chemical characteristics of natural water ( $3 \mathrm{~d}$ ed.): Department of The Interior William P. Clark, Secretary, U.S. Geological Survey Water-Supply Paper 2254, Dallas L. Peck, Director, 272.

11. Henry H.R. 1964. Effects of dispersion on salt encroachment in coastal aquifers, sea water in coastal aquifers. U.S. Geological Survey Water-Supply Paper 1613-C, 70-84, United States Government Printing Office, Washington, 95.

12. Langevin C.D., Thorne D.T., Dausman A.M., Sukop M.C., Guo W., 2008. SEAWAT Version 4: A Computer Program for Simulation of Multi-Species Solute and Heat Transport: U.S. Geological Survey Techniques and Methods Book, 6, 44.

13. Lee C., Cheng R.T. 1974. On seawater encroachment 
in coastal aquifers. Water Resources Research, 10(5), 1039-1043.

14. Marella R.L. 2015. Water withdrawals in Florida, 2012. US Department of the Interior, US Geological Survey, 2015-1156, 10.

15. McDonald M.G., Harbaugh A.W. 1988. A modular three-dimensional finite-difference ground-water flow model: U.S. Geological Survey Techniques of Water-Resources Investigations, 6, 586.

16. Motz L.H., Ali S. 2013. Saltwater intrusion and recirculation of seawater at a coastal boundary. Journal of Hydrologic Engineering, 18(1), 10-18.

17. NOAA(National Oceanic and Atmospheric Administration). 1998. Pressures on coastal environments: Population: Distribution, density and growth, in State of the Coast Report, 33.

18. NOAA's State of the Coast. 2013. National Coastal Population Report: Population Trends from 1970 to 2020. National Oceanic and Atmospheric Administration, Department of Commerce, developed in partnership with the U.S. Census Burea, 22.

19. Pinder G.F., Cooper Jr. H. 1970. A numerical technique for calculating the transient position of the saltwater front. Water Resources Research, 6(3), 875-882.

20. Reay W.G. 2004. Septic tank impacts on groundwater quality and nearshore sediment nutrient flux. Groundwater, 42(7), 1079-1089.

21. Segol G. 1993. Classic groundwater simulations: Proving and improving numerical models. Englewood Cliffs, N.J: PTR Prentice Hall, 531.

22. Segol G., Pinder G.F., and Gray W.G. 1975. A Galerkin-finite element technique for calculating the transient position of the saltwater front. Water Resources Research, 11(2), 343-347.

23. Simpson M.J., Clement T.P. 2003. Theoretical analysis of the worthiness of henry and elder problems as benchmarks of density-dependent groundwater flow models. Advances in Water Resources, 26(1), 17-31.

24. Smith A.J. 2004. Mixed convection and density-dependent seawater circulation in coastal aquifers. Water Resources Research, 40(8).

25. Stumm W., Morgan J.J. 1981. Aquatic Chemistry: An introduction emphasizing chemical equilibria in natural waters, Environmental Science and Technology: A Wiley-Interscience Series of Texts and Monographs, 2nd edition. John Wiley \& Sons, New York.

26. Szymczycha B., Kłostowska Ż., Lengier M., Dzierzbicka-Głowacka L. 2020. Significance of nutrient fluxes via submarine groundwater discharge in the Bay of Puck, southern Baltic Sea. Oceanologia, 62(2), 117-125.

27. Taniguchi M., Burnett W.C., Cable J.E., Turner J.V. 2002. Investigation of submarine groundwater discharge. Hydrological Processes, 16(11), 2115-2129.

28. Valiela I., Bowen J.L., Kroeger K.D. 2002. Assessment of models for estimation of land-derived nitrogen loads to shallow estuaries. Applied Geochemistry, 17(7), 935-953.

29. Valiela I., Teal J. M., Volkmann S., Shafer D., Carpenter E.J. 1978. Nutrient and particulate fluxes in a salt marsh ecosystem: Tidal exchanges and inputs by precipitation and groundwater 1. Limnology and Oceanography, 23(4), 798-812.

30. Voss C.I. 1984. A finite-element simulation model for saturated-unsaturated, fluid-density-dependent ground-water flow with energy transport or chemically-reactive single-species solute transport. Water Resources Investigation Report, 84, 4369.

31. Voss C.I., Souza W.R. 1987. Variable density flow and solute transport simulation of regional aquifers containing a narrow freshwater-saltwater transition zone. Water Resources Research, 23(10), 1851-1866.

32. Zheng C., Wang P. 1999. MT3DMS- a modular three-dimensional multispecies transport model for simulation of advection, dispersion, and chemical reaction of contaminants in ground-water systems: Documentation and user's guide. Jacksonville, Florida. Contact Report SERDP-99-1, U.S. Army Corps of Engineers. 